\title{
Association between 5-HTTLPR and borderline personality disorder traits among youth
}

\section{Benjamin L. Hankin ${ }^{1}$, Andrea L. Barrocas ${ }^{1}$, Jessica Jenness ${ }^{1}$, Caroline W. Oppenheimer ${ }^{1}$, Lisa S. Badanes ${ }^{1}$, John R. Z. Abela ${ }^{2}$, Jami Young ${ }^{2}$ and Andrew Smolen ${ }^{3}$}

1 Department of Psychology, University of Denver, Denver, CO, USA

2 Department of Psychology, Evolution and Human Behavior, Rutgers University, New Brunswick, NJ, USA

3 Institute for Behavior Genetics, University of Colorado-Boulder, Boulder, CO, USA

\section{Edited by:}

William Copeland, Duke University, USA

\section{Reviewed by:}

Robert R. Althoff, University of Vermont, USA

William Copeland, Duke University, USA

Charles Richard Jonassaint, Johns Hopkins University, USA

*Correspondence:

Benjamin L. Hankin, Department of Psychology, University of Denver, 2155 South Race Street, Denver, CO 80208 , USA.

e-mail:ben.hankin@psy.du.edu
This study provides the first genetic association examination of borderline personality disorder (BPD) traits in children and adolescents (ages 9-15) using two independent samples of youth recruited from the general community. We tested the a priori hypothesis that the serotonin transporter promoter gene (5-HTTLPR) would relate specifically to BPD traits in youth. This association was hypothesized based on prior genetic association research with BPD adults and theory positing that emotion dysregulation may be a core risk process contributing to BPD. Youth provided DNA via buccal cells. Both youth and a parent completed self-report measures assessing youth's BPD traits and depressive symptoms. Results from both Study $1(N=242)$ and an independent replication sample of Study $2(N=144)$ showed that carriers of the short allele of 5-HTTLPR exhibited the highest levels of BPD traits. This relation was observed even after controlling for the substantial co-occurrence between BPD traits and depressive symptoms. This specific association between 5-HTTLPR and BPD traits among youth supports previous genetic associations with adults diagnosed with BPD and provides preliminary support for a developmental extension of etiological risk for BPD among youth.

Keywords: youth, borderline personality disorder, molecular genetics, serotonin

\section{INTRODUCTION}

Borderline personality disorder (BPD) is a severe and persistent psychopathological disorder characterized by unstable and intense interpersonal relationships, impulsive behavior, and extreme dysregulated mood and emotion, among other traits, leading to marked difficulty with cognitive, emotional, and behavioral functioning (American Psychiatric Association, 2000). Most of the research with BPD has been conducted with adult samples. Adults with BPD experience significant impairment, engage in frequent parasuicidal and suicidal behaviors, and have substance use problems (e.g., Silk et al., 1995; Skodol et al., 2002a,b; Welch and Linehan, 2002; Yen et al., 2004). Of the available research with youth, prospective longitudinal research with children and adolescents (ages 9-18), recruited from the general community, shows that dimensionally assessed BPD traits predict many subsequent negative outcomes, maladjustment, and impairment later in adulthood. Specifically, BPD traits assessed in youth predict future diagnosis of BPD in adulthood (Winograd et al., 2008), as well as other forms of maladjustment, including eating and weight problems (Johnson et al., 2006a), a greater likelihood of developing Axis I disorders (Johnson et al., 2006b), lower life satisfaction (Winograd et al., 2008), and diminished quality of life (Chen et al., 2006).

Such developmental epidemiological data clearly highlight the need for additional research investigating etiological risk factors and processes that may contribute to BPD in youth. However, relatively little research has examined risks to BPD in youth (Cicchetti and Crick, 2009). Although BPD cannot be diagnosed before adulthood (Al-Alem and Omar, 2008), it is important to examine theoretically based developmental precursors of BPD during childhood and adolescence (Crick et al., 2007) that may influence later development of BPD. The main purpose of this study was to conduct the first candidate gene association study of BPD traits in youth in order to provide initial, preliminary data on molecular genetic risks to BPD among children and adolescence.

Recently, Crowell et al. (2009) articulated a developmentally sensitive biosocial model that delineated potential precursors to BPD among youth that may contribute to BPD over time (see also Putnam and Silk, 2005). This model proposes various developmental processes that begin in childhood and become ingrained as patterns become increasingly persistent, compound over time, and eventually lead to BPD in adulthood. A central component of this model and other BPD theories is that at-risk individuals have a genetically mediated predisposition for emotion dysregulation, which leads to greater sensitivity to emotional stimuli, trouble regulating these increased emotions, and difficulty returning to a neutral emotional state. Given these theoretical models, we examined polymorphisms in the promoter region of the serotonin transporter gene (5-HTTLPR) as a putative specific genetic risk that is hypothesized to underlie emotion dysregulation.

5-HTTLPR is one promising candidate gene to examine in association with BPD traits because of its link with several core symptoms and features of BPD, including emotional dysregulation and lability, stress reactivity, and impulsivity (e.g., Frankle et al., 2005; Hoefgen et al., 2005; Putnam and Silk, 2005; Gotlib et al., 2008; Beauchaine et al., 2009; Caspi et al., 2010). The variant site of the serotonin transporter gene is commonly known as 5-HTTLPR. 
Variants of 5-HTTLPR are the long allele (l), consisting of 16 copies of an approximately 22 base pair (bp) repeat unit, and a short allele comprised of 14 copies. (s), The $s$ allele is associated with decreased transcriptional efficiency leading to reduced reuptake of serotonin in the pre-synaptic neuron (Lesch et al., 1996; Canli and Lesch, 2007). One or two copies of the $s$ allele have been associated with a BPD diagnosis in adults (Ni et al., 2006; Lis et al., 2007) as well as BPD features among adults, such as emotional lability (Frankle et al., 2005; Hoefgen et al., 2005) and greater sensitivity to emotional stimuli (Beevers et al., 2009a,b; Caspi et al., 2010). For example, 5-HTTLPR is associated with amygdala activation in response to emotional faces (Hariri et al., 2005), and BPD adults exhibit dysregulated amygdala activity (Donegan et al., 2003; Ebner-Priemer et al., 2005). Additionally, research with women diagnosed with $\mathrm{BPD}$ found that serotonin receptor binding (5HT [sub]2A) was dysregulated in the hippocampus, and this association was independent of other factors that frequently co-occur with BPD (e.g., depressed mood, impulsivity, aggression, suicidality, and child abuse; Soloff et al., 2007). Still, despite such positive evidence suggestive of an association between 5-HTTLPR and many aspects of BPD, it also worth noting that meta analysis shows no consistent association between 5-HTTLPR and secondary aspects of BPD, such as depressed mood or broad negative affect (Anguelova et al., 2003).

No research, to our knowledge, has investigated association between any candidate gene and BPD traits among youth. The lack of research investigating molecular genetic associations with BPD traits among youth and the equivocal associations with BPD features in adult samples (e.g., no association between 5-HTTLPR and depression; positive associations with emotional lability and reactivity) motivated the present research. The main purpose of this study was to examine whether 5-HTTLPR was associated with BPD traits specifically in youth. In addition to assessing BPD traits, we also examined the discriminant validity of this hypothesized association. Specifically, we measured depressive symptoms, which have not shown reliable associations with 5-HTTLPR, to examine whether BPD traits are associated with 5-HTTLPR specifically, as opposed to depressive symptoms that frequently co-occur with BPD. The goal of this secondary hypothesis was to investigate whether we could "explain away" the expected association between 5-HTTLPR and BPD traits by controlling for the overlap with depressive symptoms.

In summary and in response to the paucity of research on developmental antecedents to BPD traits (Crick et al., 2005; Cicchetti and Crick, 2009), this study examined the main hypothesis that borderline personality traits in youth would relate specifically to the short allele of 5-HTTLPR, which has been linked to emotion dysregulation, a hypothesized core process underlying BPD. Finally, given well-known lack of replication and inconsistent findings in molecular genetic association studies, we included an independent replication sample to investigate whether our a priori hypothesized association between BPD traits and 5-HTTLPR in youth was maintained and replicated.

\section{STUDY 1}

\section{METHODS}

\section{Participants and procedures}

Children and adolescents were recruited by letters mailed to families with a child in 3rd, 6th, or 9th grades of public schools from a metropolitan area in the Mountain West. Approximately 2,000 families had a child in 3rd, 6th, or 9th grade in a participating school district, and therefore were eligible to receive letters. The short invitation letter stated that we were conducting a study on social and emotional development in children and adolescents and requested that interested participants call the laboratory to receive more detailed information on the study. Of the brief introductory letters sent by the school districts, 337 families were counted as contacted as a parent responded to the letter and called the laboratory for more information. The 337 contacted parents called the laboratory and responded to a brief phone screen that established that both the parent and child were fluent in English, and the child did not carry an autism spectrum or psychotic disorder and had an IQ $>70$. Of the 337 initially contacted families, 252 (74\%) qualified as a study participant as they met criteria and arrived at the laboratory for the assessment. The remaining 85 $(26 \%)$ are considered non-participants for the following reasons: 3 (1\%) were excluded due to child with autism spectrum disorder or non-English speaking family, 12 (3\%) declined after learning about the study's requirements, 49 (14\%) were scheduled but did not arrive for assessment, and 21 (6\%) were never reached to schedule an assessment. In sum, the present study has a participation rate of $74 \%$. Our participation rate is above the $70 \%$ rate recommended by epidemiologists for having a representative sample of the target population (Tolonen, 2005; Tolonen et al., 2005) and is comparable to that found in previous community-based, general samples of youth psychopathology (e.g., 61\% in Lewinsohn et al., 1993).

Participants were 252 youth ranging in age from 9 to 15 $(M=11.4, \mathrm{SD}=2.27)$. Table 1 shows descriptive statistics for the sample. The present sample, drawn from the general community of youth attending public schools, was representative of the broader population of the geographical area from which the sample was drawn, in terms of demographic characteristics, socioeconomic status, ethnicity, and race.

Parents provided informed written consent for their participation and for their child; youth provided written assent. Both the parent and child completed a battery of questionnaires about the child, and youth DNA was collected via saliva. The Institutional Review Board approved all procedures. Youth and parents were reimbursed for participation.

\section{Measures}

Borderline personality disorder traits. The Children in Community Self-Report (CIC-SR; Crawford et al., 2005) was used to measure BPD traits in youth. The CIC-SR was based on and written to assess DSMIII-R symptoms and features of personality disorders. We used the 17 items from the BPD sub-scale from the CIC-SR to assess BPD symptoms. There are few reliable and valid methods available for assessing personality disorder traits in youth (Crick et al., 2007). We chose the CIC-SR to assess BPD traits in our sample of youth recruited from the general community because Cohen and colleagues' longitudinal Children in the Community study, comprised of a general community sample, has shown this measure to have strong reliability and validity (e.g., Crawford et al., 2005; Winograd et al., 2008).

Borderline personality disorder symptoms are measured using a 1-4 Likert scale, and items are summed together to provide a dimensional measure in which higher scores indicate greater severity of BPD features. Example items assessing BPD symptoms include "I become frantic when I think someone I care about might 
Table 1 | Descriptive statistics for samples 1 and 2.

\begin{tabular}{|c|c|c|}
\hline Variable & Study $1(N=242)$ & Study $2(N=144)$ \\
\hline Sex & $57 \%$ girls & $57 \%$ girls \\
\hline \multicolumn{3}{|l|}{ GRADE } \\
\hline 3rd & $31 \%$ & $28 \%$ \\
\hline 6 th & $41 \%$ & $26 \%$ \\
\hline 9th & $28 \%$ & $46 \%$ \\
\hline \multicolumn{3}{|l|}{ ETHNICITY } \\
\hline Latino & $19 \%$ & $10 \%$ \\
\hline Non-Latino & $81 \%$ & $90 \%$ \\
\hline \multicolumn{3}{|l|}{ RACE } \\
\hline Caucasian & $68 \%$ & $67 \%$ \\
\hline African-American & $22 \%$ & $13 \%$ \\
\hline Asian/Pacific Islander & $3 \%$ & $17 \%$ \\
\hline Other/mixed race & $7 \%$ & $3 \%$ \\
\hline \multicolumn{3}{|c|}{ SOCIOECONOMIC STATUS } \\
\hline \multicolumn{3}{|c|}{ Parental income } \\
\hline Mdn & $\$ 70,000$ & $\$ 40,000$ \\
\hline Range & $\$ 10,000-200,000$ & $\$ 3,000-285,000$ \\
\hline Free/reduced lunch & $24 \%$ & $26 \%$ \\
\hline \multicolumn{3}{|c|}{ PARENT INFORMATION } \\
\hline$\%$ Mothers & 87 & 100 \\
\hline Married & $73 \%$ & $52 \%$ \\
\hline Single & $11 \%$ & $16 \%$ \\
\hline Divorced/separated & $15 \%$ & $32 \%$ \\
\hline Widowed & $1 \%$ & $0 \%$ \\
\hline \multicolumn{3}{|c|}{ YOUTHS' BPDTRAITS - YOUTH REPORT } \\
\hline$\alpha$ & 0.90 & 0.89 \\
\hline$M(S D)$ & $28.95(9.77)$ & $27.87(7.66)$ \\
\hline \multicolumn{3}{|c|}{ YOUTHS' BPDTRAITS - PARENT REPORT } \\
\hline$\alpha$ & 0.95 & 0.87 \\
\hline$M(\mathrm{SD})$ & $25.39(11.3)$ & $24.44(9.2)$ \\
\hline \multicolumn{3}{|c|}{ CDI - YOUTH REPORT } \\
\hline$\alpha$ & 0.85 & 0.84 \\
\hline$M(S D)$ & $6.87(5.0)$ & $5.97(4.02)$ \\
\hline \multicolumn{3}{|c|}{ CDI - PARENT REPORT } \\
\hline$\alpha$ & 0.83 & 0.83 \\
\hline$M(\mathrm{SD})$ & $5.69(5.69)$ & $5.47(5.80)$ \\
\hline
\end{tabular}

leave" and "I often feel empty inside." In addition to the youth reporting on their own personality disorder traits with the CIC-SR, we also modified slightly some of the wording of items to create a parent-report version on youths' personality disorder traits (i.e., the CIC-PR) to enable multiple informants of BPD traits in youth. The CIC-SR items were rewritten so that parents could answer the questions about their children (e.g., "My child complains of feeling empty inside."). Table 1 shows descriptive statistics. There was little missing data (99\% complete for SR; 98\% complete for PR).

\section{Depressive symptoms}

The Children's Depression Inventory (CDI; Kovacs, 1985) assessed youths' depressive symptoms. Both the child (CDI-C) and parent (CDI-P) reported on the child's level of depressive symptoms to enable multiple informants. CDI-C and CDI-P scores were moderately correlated $(r=0.34 p<0.001)$, so they were standardized and averaged together to form an overall depressive symptoms score. The CDI has good reliability and validity (Klein et al., 2005). Table 1 shows descriptive statistics, which are comparable to published norms (Kovacs, 1985) and prior research with general community samples (Petersen et al., 1993).

\section{Genotyping}

Children provided buccal cells for DNA collection via Oragene ${ }^{\circledast}$ kits from DNA Genotek (Ottawa, ON, Canada) and genomic DNA was collected and isolated using standard salting out and solvent precipitation methods. The 5-HTTLPR alleles were assayed (Anchordoquy et al., 2003) and modified by using primers reported by Hu et al. (2005). The rs25531 SNP genotypes $\left(\mathrm{L}_{\mathrm{A}} \mathrm{vs} \mathrm{L}_{\mathrm{G}}\right)$ were obtained by incubating the PCR products with MspI (Wendland et al., 2006). Samples were analyzed on an ABI PRISM ${ }^{\circledast} 3130 x \mathrm{xl}$ Sequencer. There was high success rate ( $98 \%$ of samples) for DNA extraction and genotyping. For the tri-allelic analyses, three groups of participants were formed based on their genotyping: children homozygous for the lower expressing $\mathrm{S}$ or $\mathrm{L}_{\mathrm{G}}$ alleles, those heterozygous, and those homozygous for the higher expressing $\mathrm{L}_{\mathrm{A}}$ allele. For traditional biallelic analyses, trichotomous groups of SS, SL, and LL genotypes were formed.

5-HTTLPR polymorphisms were in Hardy-Weinberg equilibrium. Genotype frequencies for traditional 5-HTTLPR were 33\% $\mathrm{L} / \mathrm{L}, 45 \% \mathrm{~S} / \mathrm{L}$, and $22 \% \mathrm{~S} / \mathrm{S}$. Genotype frequencies for tri-allelic 5-HTTLPR were $21 \% \mathrm{~L}_{\mathrm{A}}$ homozygotes, $46 \%$ heterozygotes, and $33 \%$ homozygotes for $S / L_{G}$. Neither 5-HTTLPR genotype nor allelic frequencies varied significantly by race (highest $\chi^{2}<1.37$ ).

\section{RESULTS}

Youth and parent reports of youths' BPD traits were correlated $r=0.55, p<0.001$. Independent $t$-tests showed a slight, but significant, sex difference for youth-reported $\mathrm{BPD}(t=1.98, p=0.05$; girls' $M=30.11, \mathrm{SD}=9.83$; boys' $M=28.08, \mathrm{SD}=9.33)$ but no sex difference for parent-reported BPD $(t=0.63, p=0.52)$. Likewise, a one-way ANOVA revealed no significant grade differences for either youth-reported $(F=0.72, p=0.49)$ or parent-reported $(F=0.97$, $p=0.38) \mathrm{BPD}$ traits and no sex $\times$ grade interaction for either informant. There were no race or ethnicity differences in BPD traits and no higher order interactions (sex or grade) involving race/ethnicity.

Study 1 had $95 \%$ power to detect an association of moderate effect size, which is what was obtained in a prior case-control study with adults (Ni et al., 2006). ANOVA was used to examine mean differences between youths' BPD trait scores and association with genotype (5-HTTLPR). We conducted analyses in two ways with youth with complete data on both BPD traits and 5-HTTLPR (i.e., $N=242$ ). First, we examined youths' BPD scores separately as reported by youth and parent. Second, we standardized and averaged together youth and parent reports to form an overall composite BPD trait score. Both approaches provided the same significance and pattern of results. Given the moderate overlap between parent- and youth-reported scores for youths' BPD traits and the similar pattern of results when analyzed separately, we report only those analyses when parent- and youth-reported traits were combined together for parsimony.

We conducted an omnibus one-way ANOVA with all fixed factors (grade, sex, genotype) included to examine possible higher order interactions and main effects in one analysis. None of the 
higher order interactions was significant: 3 (grade) $\times 2($ sex $) \times 3$ (5-HTTLPR biallelic genotype) ANOVA, $F(4,222)=1.34, p=0.25$; $2($ sex $) \times 3(5$-HTTLPR), $F(2,234)=1.27, p=0.28$; and 3 (grade $) \times 3$ $(5$-HTTLPR $), F(4,233)=1.88, p=0.11$. However and consistent with a priori prediction, youths' BPD traits differed as a function of 5-HTTLPR, $F(2,239)=4.33, p=0.01$. This significant genetic association is shown in Table 2 for both youth-and parent-reported BPD traits in the child. Planned follow-up analyses showed that youth carrying one or two copies of the short allele of 5-HTTLPR exhibited the highest levels of BPD traits, whereas L/L youth had relatively lower BPD traits. The same pattern of results was obtained when tri-allelic 5-HTTLPR was examined.

No significant differences were observed for depressive symptoms as a function of 5-HTTLPR: $F(2,239)=0.56, p=0.55$. Last, ANCOVA was used to examine whether the 5-HTTLPR differences for BPD traits were maintained after controlling for the influence of depressive symptoms. Youths' BPD traits continued to differ as a function of 5-HTTLPR, $F(2,238)=4.04, p=0.02$, even after controlling for CDI. Also as expected, youths' depressive symptoms were significantly associated with BPD symptoms, $F(1,238)=31.90, p<0.001$.

\section{STUDY 2 \\ METHODS \\ Participants and procedures}

The same procedures and exclusion criteria described for Study 1 were used in Study 2. Briefly, approximately 1,000 families had a child in 3rd, 6th, or 9th grade in participating school districts from East Coast metropolitan areas and, therefore, were eligible to receive letters. Of the brief introductory letters sent by the school districts, 202 families were counted as contacted because a parent responded to the letter and called the laboratory for more information. Of the 202 initially contacted families, 148 (73\%) qualified as a study participant as they met criteria and arrived at the laboratory for the first assessment. The remaining 54 (27\%) are considered nonparticipants for the following reasons: 1 was excluded due to child with autism spectrum disorder; 10 (4\%) declined after learning about the study's requirements, 36 (18\%) were scheduled but did not arrive for assessment, and 7 (4\%) were never reached to schedule an assessment. In sum, the present study has a participation rate of $73 \%$.

Table 2 | 5-HTTLPR differences for youth-reported and parent-reported borderline personality disorder traits among youth.

\begin{tabular}{llll}
\hline & \multicolumn{3}{c}{ Genotype groups } \\
\cline { 2 - 4 } & SS $(\boldsymbol{n}=\mathbf{5 1})$ & SL $(\boldsymbol{n}=\mathbf{1 1 0})$ & LL $(\boldsymbol{n}=\mathbf{8 1})$ \\
STUDY 1 & & & \\
BPD traits - youth report & $32.56(10.3)^{\mathrm{a}}$ & $30.22(8.99)^{\mathrm{a}}$ & $24.91(9.88)^{\mathrm{b}}$ \\
BPD traits - parent report & $28.63(14.7)^{\mathrm{a}}$ & $27.58(9.62)^{\mathrm{a}}$ & $24.97(9.75)^{\mathrm{b}}$ \\
\cline { 2 - 4 } & $\mathbf{S S}(\boldsymbol{n}=\mathbf{3 9})$ & $\mathbf{S L}(\boldsymbol{n}=\mathbf{6 9})$ & $\mathbf{L L}(\boldsymbol{n}=\mathbf{3 6})$ \\
& & & \\
STUDY 2 & & $27.87(6.4)^{\mathrm{a}}$ & $23.13(7.78)^{\mathrm{b}}$ \\
BPD traits - youth report & $29.02(7.95)^{\mathrm{a}}$ & $25.58(8.9)^{\mathrm{a}}$ & $21.56(9.73)^{\mathrm{b}}$ \\
BPD traits - parent report & $26.32(9.7)^{\mathrm{a}}$ & 25.5 & \\
\hline
\end{tabular}

Means and SDs (in brackets) for borderline personality disorder trait scores. Groups with different superscripts differed significantly at $p<0.05$.
Participants were 148 youth ranging in age from 9 to 15 $(M=11.4, \mathrm{SD}=2.27)$. Table 1 shows descriptive statistics for the sample. The composition of this sample, in terms of ethnicity, race, gender, and socioeconomic status, is comparable to that of the community and school districts from which the sample was recruited.

Parents provided informed written consent for their participation and for their child; youth provided written assent. Both the parent and child completed a battery of questionnaires about the child, and youth DNA was collected via saliva. The Institutional Review Board approved all procedures. Youth and parents were reimbursed for participation.

\section{Measures}

The same measures were used in Study 2 as described in Study 1. Table 1 shows descriptive statistics for the measures. There was very little missing data (99\% complete for both child and parent reports). Genotyping was performed the same as in Study 1. There was high success rate (98.6\% of samples) for DNA extraction and genotyping.

5-HTTLPR polymorphisms were in Hardy-Weinberg equilibrium. Genotype frequencies for traditional 5-HTTLPR were 25\% $\mathrm{L} / \mathrm{L}, 48 \% \mathrm{~S} / \mathrm{L}$, and $27 \% \mathrm{~S} / \mathrm{S}$. Genotype frequencies for tri-allelic 5-HTTLPR were $13 \% \mathrm{~L}_{\mathrm{A}}$ homozygotes, $49 \%$ heterozygotes, and $38 \%$ homozygotes for $S / L_{G}$. Neither 5-HTTLPR genotype nor allelic frequencies varied significantly by race (highest $\chi^{2}<1.28$ ).

\section{RESULTS}

Youth and parent reports of youths' BPD traits were correlated $r=0.52, p<0.001$. Independent $t$-tests showed no sex difference for either youth-reported BPD $(t=1.36, p=0.17)$ or parent-reported $\operatorname{BPD}(t=0.89, p=0.48)$. Likewise, a one-way ANOVA revealed no significant grade differences for either youth-reported $(F=0.35$, $p=0.71)$ or parent-reported $(F=0.48, p=0.46)$ BPD traits and no sex $\times$ grade interaction for either informant. There were no race or ethnicity differences in BPD traits and no higher order interactions (sex or grade) involving race/ethnicity.

As with Study 1, ANOVA was used to examine mean differences between youths' BPD trait scores and association with genotype (5-HTTLPR). Analyses were conducted with youth with complete data on both BPD traits and 5-HTTLPR (i.e., $N=144$ ), and we present analyses when parent- and youth-reported traits were combined together for parsimony. Based on the effect size from Study 1, there was $80 \%$ power to detect a significant main effect association with the sample size of Study 2.

No higher order interactions were significant from the omnibus one-way ANOVA with all factors included: 3 (grade) $\times 2$ $($ sex $) \times 3$ (5-HTTLPR biallelic genotype) ANOVA, $F(4,116)=0.92$, $p=0.43 ; 2$ (sex) $\times 3$ (5-HTTLPR), $F(2,138)=0.53, p=0.58$; and 3 (grade) $\times 3(5$-HTTLPR $), F(4,135)=0.355, p=0.85$. However and consistent with results from Study 1, youths' BPD traits differed as a function of 5-HTTLPR, $F(2,144)=4.97, p=0.008$. This significant genetic association is shown in the lower portion of Table 2 for both youth- and parent-reported BPD traits in the child. As with results from Study 1, youth carrying one or two copies of the short allele of 5-HTTLPR exhibited the highest levels of BPD traits, whereas L/L youth had relatively lower BPD traits. The same pattern of results was obtained when tri-allelic 5-HTTLPR was examined. 
Last and consistent with results from Study 1, no significant differences were observed for depressive symptoms as a function of 5-HTTLPR: $F(2,142)=1.04, p=0.35$. Analyses using ANCOVA showed that the 5-HTTLPR differences for BPD traits were maintained after controlling for the influence of depressive symptoms. Youths' BPD traits continued to differ as a function of 5-HTTLPR, $F(2,141)=4.34, p=0.01$, even after controlling for CDI. Also as expected, youths' depressive symptoms were significantly associated with BPD symptoms, $F(1,141)=40.36, p<0.001$.

\section{DISCUSSION}

This study provided the first investigation of the link between 5-HTTLPR and BPD traits in youth. Prior research with adults showed a significant association between BPD and 5-HTTLPR. Results showed that youth carrying one or two copies of the $s$ allele of 5-HTTLPR exhibited higher levels of BPD traits as reported by both youth and parent as informants. Moreover, discriminant validity analyses showed that 5-HTTLPR was associated specifically with BPD traits but not with depressive symptoms that are often overlapping with BPD traits. Finally, these results were maintained in an independent replication sample. These findings suggest that a specific association between the short allele of 5-HTTLPR and BPD traits is present in youth as well as adults.

Findings from both youth samples are consistent with prior research with adults and are novel in that they extend this genetic association to children and adolescents. This was the first molecular genetic association study of BPD traits in youth. Previous research has established moderate heritability (e.g., Distel et al., 2009) and specific molecular genetic association, especially with 5-HTTLPR, in adults (e.g., Ni et al., 2006; Lis et al., 2007; see New et al., 2008; Reichborn-Kjennerud, 2008, for reviews). Findings from this study extend this work downward to children and adolescents. The confidence in this genetic association is enhanced because it has been observed in research using different samples, methods, and ages, including adults diagnosed with BPD as well as the present study with two independent samples with dimensional BPD traits in youth.

Developmental psychopathology models of BPD emphasize that emotion dysregulation may be a core psychopathological process conferring risk to BPD across the lifespan (Putnam and Silk, 2005; Beauchaine et al., 2009; Crowell et al., 2009). Prior genetic research suggests that 5-HTTLPR may be associated with emotional dysregulation and stress reactivity more specifically (e.g., Gotlib et al., 2008; Caspi et al., 2010) as opposed to depressive symptoms and negative affect more broadly (e.g., Anguelova et al., 2003). The findings from both samples showing that 5-HTTLPR was associated with BPD traits in youth, but not with depressive symptoms, is consistent with these suggestions and past research (Goodman et al., 2010).

Certain strengths of the study enhance confidence in the findings. First, this study was the first to use both parents and youths as informants of BPD traits among youth. Doing so is important because it minimizes the possibility of substantial informant bias that may account for the pattern of findings. In addition, concordance between parent and youth report for youths' personality disorder traits was the same as or better than expected based on studies of agreement among informants for other emotional and behavioral problems (e.g., Achenbach et al., 1987; Cole et al., 1997). As this is the first study to use parent report of their children's personality disorder traits, the initial reliability and validity data suggest that other research can use multiple informants, including parent report, to advance knowledge on youths' personality disorder traits. Second, by utilizing a sample of youth and parents recruited from the general community, this study may have provided a stronger and more accurate test of the association between a candidate gene and BPD traits among youth. In contrast to psychiatric clinic-based samples, community-based samples are more likely to be generalizable and less prone to known problems (e.g., Berkson's bias) that can skew and distort results (e.g., Cohen and Cohen, 1984; Goodman et al., 1997). Last, an independent sample replicated the association between 5-HTTLPR and BPD traits. Both samples were adequately powered to detect significant main effect genetic associations, based on power analysis with effect sizes suggested by the available adult research. This suggests that the findings are not spurious or obtained by chance.

Despite some strengths, limitations should also be noted. First, this study design was cross-sectional. Although the preponderance of genetic association research employs cross-sectional designs to establish basic associations, future research with multiple waves of prospective follow-up data would be beneficial. Second, a self-report questionnaire of BPD symptoms was used. This provided a dimensional assessment of the severity of BPD features. Although the questionnaire we used has shown strong reliability and validity in previous longitudinal research and we used both youth and parent informants, the measure does not enable a diagnosis of BPD to be made. It would be helpful for future research to use clinical interview ratings or other objective indices of BPD (cf., Crick et al., 2005). Third, we used a candidate gene approach and examined one specific gene. Although chosen a prioribased on prior research with adults (e.g., Ni et al., 2006; New et al., 2008; Reichborn-Kjennerud, 2008) and relevant theory (e.g., Putnam and Silk, 2005; Beauchaine et al., 2009; Crowell et al., 2009), future genetic investigations could expand the scope of inquiry through the use of other candidate genes linked with emotional dysregulation and BPD (e.g., Tadić et al., 2008; Ni et al., 2009; Wagner et al., 2010) or genome wide association approaches. Finally, the sample sizes of both independent studies were small to moderate for genetic association research. Although both studies were adequately powered to detect the a priori hypothesized main effect between BPD traits and 5-HTTLPR based on the prior adult findings, future research could benefit from larger sample size and additional genetic ascertainment.

In summary, this study establishes initial, albeit preliminary, support among a community, non-referred sample of youth for a developmental downward extension of previous research with adults diagnosed with BPD demonstrating an association between BPD traits and 5-HTTLPR. By showing this genetic association in youth, a valuable first step has been taken toward initiating additional developmentally sensitive research on BPD, as recommended by Cicchetti and Crick (2009). The present research provides preliminary and promising evidence that BPD traits can be investigated during childhood and adolescence, an important period for studying genetically mediated processes prior to BPD diagnosis in adulthood.

\section{ACKNOWLEDGMENTS}

This work was supported by NIMH grant 5R01 MH077195 (Hankin and Abela). The content is solely the responsibility of the authors and does not necessarily represent the official views of the National Institute of Mental Health or National Institutes of Health. 


\section{REFERENCES}

Achenbach, T. M., McConaughy, S. H., and Howell, C. T. (1987). Child/adolescent behavior and emotional problems: implications of cross-informant correlations for situational specificity. Psychol. Bull. 101, 213-232.

Al-Alem, L., and Omar, H. A. (2008). Borderline personality disorder: an overview of history, diagnosis and treatment in adolescents. Int. J. Adolesc. Med. Health 20, 395-404.

American Psychiatric Association. (2000). Diagnostic and statistical manual of mental disorders, 4th Edn (Text Revision). Washington, DC: APA Press.

Anchordoquy, H. C., McGreary, C., Liping, L., Krauter, K. S., and Smolen, A. (2003). Genotyping of three candidate genes after whole-genome preamplification of DNA collected from buccal cells. Behav. Genet. 33, 73-78.

Anguelova, M., Benkelfat, C., and Turecki, G. (2003). A systematic review of association studies investigating genes coding for serotonin receptors and the serotonin transporter: I. Affective disorders. Mol. Psychiatry 8, 574-591.

Beauchaine, T. P., Klein, D. N., Crowell, S. E., Derbidge, C., and Gatzke-Kopp, L. (2009). Multifinality in the development of personality disorders: a biology $\times \operatorname{sex} \times$ environment interaction model of antisocial and borderline traits. Dev. Psychopathol. 21, 735-770.

Beevers, C. G., Wells, T. T., Ellis, A. J., and McGeary, J. E. (2009a). Association of the serotonin transporter gene promoter region (5-HTTLPR) polymorphism with biased attention for emotional stimuli. J. Abnorm. Psychol. 118, 670-681.

Beevers, C. G., Wells, T. T., Ellis, A. J., and McGeary, J. E. (2009b). Serotonin transporter gene promoter region polymorphism and selective processing of emotional images. Biol. Psychol. 83, 260-265.

Canli, T., and Lesch, K. P. (2007). Long story short: the serotonin transporter in emotion regulation and social cognition. Nat. Neurosci. 10, 1103-1109.

Caspi, A., Hariri, A. R., Holmes, A., Uher, R., and Moffitt, T. E. (2010). Genetic sensitivity to the environment: the case of the serotonin transporter gene and its implications for studying complex diseases and traits. Am. J. Psychiatry 167, 509-527.

Chen, H., Cohen, P., Crawford, T. N., Kasen, S., Johnson, J. G., and Berenson, K. (2006). Relative impact of young adult personality disorders on subsequent quality of life: findings of a community-based longitudinal study. J. Pers. Disord. 20, 510-523.
Cicchetti, D., and Crick, N. R. (2009). Precursors and diverse pathways to personality disorder in children and adolescents. Dev. Psychopathol.21,683-685.

Cohen, P., and Cohen, J. (1984). The clinician's illusion. Arch. Gen. Psychiatry41, 1178-1182.

Cole, D. A., Truglo, R., and Peeke, L. (1997). Relation between symptoms of anxiety and depression in children: a multitrait-multimethod-multigroup assessment. J. Couns. Clin. Psychol. 65, 110-119.

Crawford, T. N., Cohen, P., Johnson, J. G., Kasen, S., First, M. B., Gordon, K., and Brook, J. S. (2005). Self-reported personality disorder in the children in the community sample: convergent and prospective validity in late adolescence and adulthood. J. Pers. Disord. 19, 30-52.

Crick, N. R., Murray-Close, D., and Woods, K. (2005). Borderline personality features in childhood: a short-term longitudinal study. Dev. Psychopathol. 17, 1051-1070.

Crick, N. R., Woods, K., Murray-Close, D., and Han, G. (2007). "The development of borderline personality disorder: current progress and future directions." in Personality Disorders in Childhood and Adolescence, eds A. Freeman and M. A. Reinecke (Hoboken, NJ: John Wiley and Sons), 341-384.

Crowell, S. E., Beauchaine, T. P., and Linehan, M. M. (2009). A biosocial developmental model of borderline personality: elaborating and extending Linehan's theory. Psychol. Bull. 135, 495-510.

Distel, M. A., Trull, T. J., Willemsen, G., Vink, J. M., Derom, C. A., Lynskey, M., Martin, N. G., and Boomsma, D. I. (2009). The five-factor model of personality and borderline personality disorder: a genetic analysis of comorbidity. Biol. Psychiatry 66, 1131-1138.

Donegan, N.H., Sanislow, C.A., Blumberg, H. P., Fulbright, R., K., Lacadie, D., Skudlarski, P., Gore, J. C., Olson, I. R., McGlashan, T. H., and Wexler, B. E. (2003). Amygdala hyperactivity in borderline personality disorder: implications for emotional dysregulation. Biol. Psychiatry 54, 1284-1293.

Ebner-Priemer, U. W., Badeck, S., Beckman, C., Wagner, A., Feige B., Weiss, I., Lieb, K., and Bohus, M. (2005). Affective dysregulation and dissociative experience in female patients with borderline personality disorder: a startle response study. J. Psychiatr. Res. 39, 85-92.

Frankle, W. G., Lombardo, I., New, A. S., Goodman, M., Talbot, P. S., Huang, Y., Hwang, D. R., Slifstein, M., Curry, S., Abi-Dargham, A., Laruelle, M., and
Siever, L. J. (2005). Brain serotonin transporter distribution in subjects with impulsive aggressivity: a positron emission study with [11C]McN 5652. Am. J. Psychiatry 162, 915-923.

Goodman, M., New, A. S., Triebwasser, J., Collins, K. A., and Sieve, L. (2010). Phenotype, endophenotype, and genotype comparisons between borderline personality disorder and major depressive disorder. J. Pers. Disord. 24, 38-59.

Goodman, S. H., Lahey, B. B., Fielding, B., Dulcan, M., Narrow, W., and Regier, D. (1997). Representativeness of clinical samples of youths with mental disorders: a preliminary population-based study. J. Abnorm. Psychol. 106, 3-14.

Gotlib, I. H., Joorman, J., Minor, K., and Hallmayer, J. (2008). HPA axis reactivity: a mechanism underlying the association among 5-HTTLPR, stress, and depression. Biol. Psychiatry 63, 847-851.

Hariri, A. R., Drabant, E. M., Munoz, K. E., Kolachana, B. S., Mattay, V. S., Egan, M. F., and Weinberger, D. R. (2005). A susceptibility gene for affective disorders and the response of the human amygdala. Arch. Gen. Psychiatry 62, 146-152.

Hoefgen, B., Schulze, T. G., Ohlraun, S., von Widdern, O., Hofels, S., Gross, M., Heidmann, V., Kovalenko, S., Eckermann, A., Kolsch, H., Metten, M., Zobel, A., Becker, T., Nothen, M. M., Propping, P., Heun, R., Maier, W., and Rietschel, M. (2005). The power of sample size and homogenous sampling: Association between the 5-HTTLPR serotonin transporter polymorphism and major depressive disorder. Biol. Psychiatry 57, 247-251.

Hu, X., Oroszi, G., Chun, J., Smith, T. L., Goldman, D., and Schuckit, M. A. (2005). An expanded evaluation of the relationship of four alleles to the level of response to alcohol and the alcoholism risk. Alcohol Clin. Exp. Res. 29, 8-16.

Johnson, J. G., Cohen, P., Kasen, S., and Brook, J.S. (2006a). Personality disorder traits evident by early adulthood and risk for eating and weight problems during middle adulthood. Int. J. Eat. Disord. 39, 184-192.

Johnson, J. G., Cohen, P., Kasen, S., and Brook, J. S. (2006b). Personality disorders evident by early adulthood and risk for anxiety disorder during middle adulthood. Anxiety Disord. 20, 408-426.

Klein, D. N., Dougherty, L. R., and Olino, T. M. (2005). Toward guidelines for evidence-based assessment of depression in children and adolescents. J. Clin. Child Adolesc. Psychol. 34, 412-432.
Kovacs, M. (1985). The Children's Depression Inventory (CDI). Psychopharmachol. Bull. 21, 995-998.

Lesch, K. P., Dietmar, B., Heils, A., Sabol, S. Z., Greenberg, B. D., Petri, S., Benjamin, J., Muller, C. R., Hamer, D. H., and Murphy D. L. (1996). Association of anxiety-related traits with a polymorphism in the serotonin transporter gene regulatory region. Science 274, 1527-1531.

Lewinsohn, P., Hops, H., Roberts, R., Seeley, J., and Andrews, J. (1993). Adolescent psychopathology: I Prevalence and incidence of depression and other DSM-III - R disorders in high school students. J. Abnorm. Psychol. 102, 133-144.

Lis, E., Greenfiled, B., Henry, M., Guile, J. M., and Dougherty, G. (2007). Neuroimaging and genetics of borderline personality disorder: a review. J. Psychiatry Neurosci. 32, 162-173.

New, A. S., Goodman, M., Triebwasser, J., and Siever, L. J. (2008). Recent advances in the biological study of personality disorders. Psychiatr. Clin. N. Am. 31, 441-461.

Ni, X., Chan, D., Chan, K., McMain, S., and Kennedy J. L. (2009). Serotonin genes and gene-gene interactions in borderline personality disorder in a matched case-control study. Prog. Neuropsychopharmacol. Biol. Psychiatry 33, 128-133.

Ni, X., Chan, K., Bulgin, N., Sicard, T., Bismil, R., McMain, S., and Kennedy J. L. (2006). Association between serotonin transporter gene and borderline personality disorder. J. Psychiatry Res. 40, 448-453.

Petersen, A., Compas, B., Brooks-Gunn, J., Stemmler, M., Ey, S., and Grant, K. (1993). Depression in adolescence. Am. Psychol. 48, 155-168.

Putnam, K. M., and Silk, K. R. (2005). Emotion dysregulation and the development of borderline personality disorder. Dev. Psychopathol. 17, 899-925.

Reichborn-Kjennerud, T.(2008). Genetics of personality disorders. Psychiatr. Clin. N. Am. 31, 421-440.

Silk, K. R., Lee, S., Hill, E. M., and Lohr, N. E. (1995). Borderline personality disorder symptoms and severity of sexual abuse. Am. J. Psychiatry 152, 1059-1064.

Skodol, A. E., Gunderson, J. G., Pfohl, B., Widiger, T. A., Livesley, W. J., and Siever, L. J. (2002a). The borderline diagnosis I: psychopathology, comorbidity, and personality structure. Biol. Psychiatry 51, 936-950.

Skodol, A. E., Siever, L. J., Livesley, W. J., Gunderson, J. G., Pfohl, B., and Widiger, T. A. (2002b). The borderline diagnosis II: biology, genetics, 
and clinical course. Biol. Psychiatry 51, 951-963.

Soloff, P. H., Price, J. C., Meltzer, C. C., Fabio, A., Frank, G. K., and Kaye, W. H. (2007). 5HT [sub]2A[sub] receptor binding is increased in borderline personality disorder. Biol. Psychiatry 62, 580-587.

Tadić, A., Baskaya, O., Victor, A., Lieb, K., Höppner, W., and Dahme, N. (2008). Association analysis of SCN9A gene variants with borderline personality disorder. J. Psychiatr. Res. 43, 155-163.

Tolonen, H. (2005). Towards the High Quality of Population Health Surveys. Standardization and Quality Control. Helsinki: National Public Health Institute A27/2005. Available at: http://www.ktl.fi/ attachments/suomi/julkaisut/ julkaisusarja_a/2005/2005a27.pdf
Tolonen, H., Dobson, A., and Kulathinal, S. (2005). Effect on trend estimates of the difference between survey respondents and non-respondents: Results from 27 populations in the WHO MONICA Project. Eur. J. Epidemiol. 20, 887-898.

Wagner, S., Baskaya, O., Anicker, N. J., Dahmen, N., Lieb, K., and Tadić, A. (2010). The catechol o-methyltransferase (COMT) val158met polymorphism modulates the association of serious life events (SLE) and impulsive aggression in female patients with borderline personality disorder (BPD). Acta Psychiatr. Scand. 122, 110-117.

Welch, S. S., and Linehan, M. M. (2002). High-risk situations associated with parasuicide and drug use in borderline personality disorder. J. Pers. Disord. 16, 561-569.

Wendland, J. R., Martin, B. J., Kruse, M. R., Lesch, K. P., and Murphy D. L. (2006).
Simultaneous genotyping of four functional loci of human SLC6A4, with a reappraisal of 5-HTTLPR and rs25531. Mol. Psychiatry 11, 224-226.

Winograd, G., Cohen, P., and Chen, H. (2008). Adolescent borderline symptoms in the community: prognosis for functioning over 20 years. Child Psychol. Psychiatry 49, 933-941.

Yen, S., Shea, M. T., Sanislow, C. A., Grilo, C. M., Skodol A. E., Gunderson, J. G., McGlashan, T.H., Zanarini, M.C., and Morey, L.C. (2004). Borderline personality disorder criteria associated with prospectively observed suicide behavior. Am. J. Psychiatry 161, 1296-1298.

Conflict of Interest Statement: The authors declare that the research was conducted in the absence of any commercial or financial relationships that could be construed as a potential conflict of interest.
Received: 07 July 2010; accepted: 16 February 2011; published online: 01 March 2011.

Citation: Hankin BL, Barrocas AL Jenness J, Oppenheimer CW, Badanes LS, Abela JRZ, Young J and Smolen A (2011) Association between 5-HTTLPR and borderline personality disorder traits among youth. Front. Psychiatry 2:6. doi: 10.3389/ fpsyt.2011.00006

This article was submitted to Frontiers in Child and Neurodevelopmental Psychiatry, a specialty of Frontiers in Psychiatry.

Copyright (c) 2011 Hankin, Barrocas, Jenness, Oppenheimer, Badanes, Abela, Young and Smolen. This is an open-access article subject to an exclusive license agreement between the authors and Frontiers Media SA, which permits unrestricted use, distribution, and reproduction in any medium, provided the original authors and source are credited. 